\title{
BMJ Open Maternal and perinatal risk factors for childhood cancer: record linkage study
}

\author{
Sohinee Bhattacharya, ${ }^{1}$ Marcus Beasley, ${ }^{1}$ Dong Pang, ${ }^{2}$ Gary J Macfarlane ${ }^{1}$
}

To cite: Bhattacharya $S$, Beasley M, Pang D, et al. Maternal and perinatal risk factors for childhood cancer: record linkage study. BMJ Open 2014;4:e003656. doi:10.1136/bmjopen-2013003656

- Prepublication history for this paper is available online. To view these files please visit the journal online (http://dx.doi.org/10.1136/ bmjopen-2013-003656)

Received 25 July 2013 Revised 5 November 2013 Accepted 8 November 2013

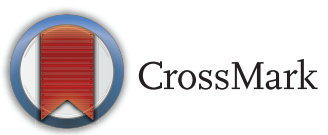

${ }^{1}$ Epidemiology Group, Division of Applied Health Sciences, University of Aberdeen, Aberdeen, UK ${ }^{2}$ Institute of Health Research, University of Bedfordshire, Bedfordshire, UK

Correspondence to Dr Sohinee Bhattacharya; sohinee.bhattacharya@abdn. ac.uk

\section{ABSTRACT}

Objective: To investigate maternal and perinatal risk factors for childhood cancer.

Study design: Case-control analysis of linked records from the Aberdeen Maternity and Neonatal Databank with the Scottish Cancer Registry and the General Registry of Births and Deaths in Scotland was carried out.

Setting: Aberdeen, Scotland.

Participants: Cases $(n=176)$ comprised children diagnosed with cancer under 15 years or recorded as having died of cancer. Four controls per case were matched by age and gender.

Risk factors tested: Maternal age, body mass index, social class, marital status and smoking as well as preeclampsia, antepartum haemorrhage and previous miscarriage, gestational age, birth weight and Apgar scores were compared between groups to test for association with cancer. ORs with $95 \% \mathrm{Cls}$ were calculated using conditional logistic regression in univariable and multivariable models.

Results: Of the maternal characteristics tested, mother's age at delivery (cases mean 28.9 (SD 5.6) years vs controls mean 30.2 (SD 4.6), $p=0.002$ ) and smoking status (38.6\% smokers among cases, $29.7 \%$ among controls, $p=0.034$ ) were found to be different between groups. Of the perinatal factors tested, low Apgar score at 5 min (adjusted OR (AOR) $4.59,95 \% \mathrm{Cl}$ 1.52 to 13.87 ) and delivery by caesarean section (AOR $1.95,95 \% \mathrm{Cl} 1.30$ to 2.92$)$ showed statistically significant associations with childhood cancer in the multivariable model.

Conclusions: Younger maternal age, maternal smoking, delivery by caesarean section and low Apgar score at 5 min were independently associated with increased risk of childhood cancer. These general findings should be interpreted with caution as this study did not have the power to detect any association with individual diagnostic categories of childhood cancer.

\section{INTRODUCTION}

Childhood cancer has been increasing in Scotland. A published report estimates that its incidence has risen from an age standardised rate of 120 cases per million population in the time period $1983-1987$ to 161 cases per million in the period 2003-2007. ${ }^{1}$

\section{Strengths and limitations of this study}

- Detailed and contemporaneous recording of data in the databases eliminated recall and reporting bias.

- The large number of social and demographic variables recorded in the Aberdeen Maternity and Neonatal Databank (AMND) enabled incorporation of most potential covariates in the analysis.

- Inadequate power to detect some weak associations reported previously in the literature.

- The number of cases according to site-specific cancer diagnosis was too small in our sample to allow any subgroup analysis.

The reason for this increasing trend remains unexplained as the aetiopathogenesis of childhood cancer is poorly understood. As most of the children present with cancer in the first few years of life, epidemiologists hypothesise that prenatal and perinatal exposures may have a part to play in its pathogenesis. The evidence surrounding this is, however, conflicting. While some researchers have found associations of younger maternal age at delivery ${ }^{2}$ maternal anaemia, ${ }^{3}{ }^{4}$ history of miscarriage, ${ }^{256}$ maternal overweight ${ }^{7}$ and smoking $^{8}$ with some childhood cancers, others have found no such associations. ${ }^{9-11}$ Fetal growth is perhaps the most investigated perinatal risk factor for childhood cancer ${ }^{712}{ }^{13}$; but the authors report conflicting results. While specific central nervous system tumours have been found to be associated with intrauterine growth restriction (IUGR), the overall risk was small. ${ }^{12}$ Therefore, apart from the associations with Down's syndrome and in utero exposure to radiation, research into the maternal and perinatal risk factors has remained inconsistent, the results limited by small sample sizes and recall or reporting bias.

Our objective was, therefore, to investigate the maternal and perinatal risk factors for childhood cancer, specifically to examine the effects of IUGR, preterm birth and birth asphyxia on the development of childhood 
cancer in the offspring, taking advantage of the opportunities offered by record linkage of a cancer registry with a local birth register.

\section{METHODS}

\section{Data sources}

The Aberdeen Maternity and Neonatal Databank (AMND) holds data for all Aberdeen City births from 1950 to the present, and includes all reproductive events to women resident in a defined geographical area with a relatively stable population. The AMND records all births occurring at the Aberdeen Maternity Hospital, the only maternity hospital serving the population of Aberdeen city and district. The exposure variables in terms of potential maternal and perinatal risk factors were derived from the AMND. The Scottish Cancer Registry has been in existence since 1951 and was complete up to 2010, at the time of the present analysis. The cases of childhood cancer were identified from this register.

\section{Data linkage}

All children born between 1993 and 2006 were identified from the AMND. Their records were linked to the Cancer Registry in Scotland (SMR 06) and the General Registry of Births and Deaths in Scotland (GRO-S), using deterministic matching. The linkage was carried out by data analysts from the Information and Services Division of National Health Service (NHS) Scotland using Community Health Index (CHI) numbers. The $\mathrm{CHI}$ number is a number unique to all individuals registered with a general practice in Scotland and recorded in both databases used in this study. In a small proportion of cases where CHI number was not available $(6 \%)$, probabilistic matching using surname, date of birth and postcode was used. After data linkage, all identifying information, including CHI numbers, were removed, and an anonymised dataset was provided for analysis.

\section{Study design}

A case-control study design was employed. Cases comprised all children identified as above from the AMND who were diagnosed with cancer under 15 years of age in Scotland as recorded in the Scottish Cancer Registry or recorded as having died of cancer. Controls were selected from the pool of children not diagnosed as having cancer, matched by age and gender using four controls per case.

Twins and multiple births were excluded as were stillbirths and early neonatal deaths. As Down's syndrome is known to be associated with a higher risk of acute lymphoblastic leukaemia (ALL) as well as myeloid leukaemia of Down's syndrome, all cases of diagnosed Down's syndrome were excluded. Moreover, those children who had died of non-cancer causes prior to their 15 th birthday, as identified from GRO-S, were also excluded.
Exposure and outcome variables used in the analysis

Maternal sociodemographic factors such as age at delivery, body mass index, Registrar General's occupationbased social class, marital status, history of miscarriage and smoking habits were extracted from the AMND. Any complications recorded during the index pregnancy such as pre-eclampsia, gestational hypertension and antepartum haemorrhage as well as mode of delivery, gestational age at delivery, birth weight, Standardised Birthweight Score $^{14}$ and Apgar score at 1 and $5 \mathrm{~min}$ were also extracted. Data extractors were blind to the case-control status of the individual children.

The outcome variables obtained from the Cancer Registry in Scotland were in the form of a binary variable (yes/no) indicating whether or not a cancer record was present, and, if present, the site of cancer was given as per International Classification of Diseases (ICD) codes. Similarly, death records with up to 10 different causes of death given by ICD codes were obtained from linking with GRO-S.

\section{Statistical analysis}

All analyses were conducted using STATA V.11 (STATA Corp, Texas, USA). Maternal baseline characteristics were compared between children diagnosed with cancer and controls using independent two-sample t tests and $\chi^{2}$ tests. Maternal complications such as gestational hypertension, pre-eclampsia, antepartum haemorrhage and history of miscarriage were compared between the cases and controls using univariate conditional regression to calculate ORs with $95 \%$ CIs. Similarly, perinatal factors such as gestation at birth, birth weight, IUGR measured by Standardised Birthweight Score and Apgar score at 1 and $5 \mathrm{~min}$ were also tested in univariate models for any association with childhood cancer. Then a multivariable conditional logistic regression model was fitted that included as independent variables all the risk factors tested on univariate analysis. The possibility of cancer subgroup analysis was considered according to the International Classification of Childhood Cancer (ICCC), but the number of cases in each subgroup was too small to warrant this.

\section{Missing data}

Apart from the variables describing maternal baseline characteristics, the other risk factors did not have any missing values. There were 18 controls and 1 case with missing smoking data. The multivariable model was repeated including and excluding the individuals with missing information. We used two methodological approaches to handle this-listwise deletion-that is, not including any group where one person in that group has missing data, and imputation by creation of a missing value (999) so that all cases and controls were included in the analyses. The ORs obtained by both methods are presented. 


\section{RESULTS}

There were 62375 deliveries between 1993 and 2006 as identified from the AMND. After excluding Down's syndrome cases, twins and multiple births, stillbirths and early neonatal deaths, there were 60117 children eligible for linkage with the Cancer Registry. It was possible to link 43591 of these children to the cancer and GRO-S databases. Among the children with linked data, 106 had died of non-cancer causes before they reached the age of 15 and were therefore excluded from the analysis. Of the remainder, 176 children were found to have a record in the Cancer Registry, giving a cumulative incidence rate of childhood cancer up to 15 years of 4.05 per 1000 deliveries. They constituted the cases for the analysis and were matched in a $1: 4$ ratio by year of birth and sex from the pool of remaining children without any records of cancer to obtain 704 controls. As D40, D44, D47 and D48 codes in ICD-10 do not correspond to cancer diagnosis in ICCC, the analyses were repeated excluding these codes.

Maternal baseline characteristics were compared between cases and matched controls in table 1 . Of the maternal characteristics tested, mother's age at delivery (cases mean 28.9 years, SD 5.6; controls mean 30.2, SD 4.6; $\mathrm{p}=0.002)$ and smoking status $(38.6 \%$ current or ex-smokers among cases, 29.7\% among controls, $\mathrm{p}=0.022$ ) were found to be significantly different between the two groups.

Table 2 presents the unadjusted ORs with 95\% CIs for all the perinatal potential risk factors for childhood cancer. Of the factors tested, preterm birth (OR 2.23 (1.31 to 3.79)), low birth weight (OR 1.87 (1.03 to 3.39)), low Apgar score at $5 \mathrm{~min}$ (OR 5.01 (1.73 to
14.54)) and delivery by caesarean section (OR 1.77 (1.23 to 2.56)) were found to be statistically significant. Subsequently, these factors were adjusted for maternal age at delivery and smoking. As the maternal smoking variable had some missing data, we handled this using two approaches-listwise deletion and imputation of a missing value. After these adjustments, low birth weight no longer remained significant, but the other associations were strengthened.

After conducting the univariate analyses, multivariable models were fitted including maternal age, smoking status, pre-eclampsia, placenta praevia, preterm birth, low birth weight, low Apgar at 5 min and delivery by caesarean as independent variables (results in table 3). Similar to the previous analyses, we used two methods of listwise deletion and imputation of the missing value to adjust for smoking status. Of the perinatal factors tested, Apgar score below 7 at 5 min (adjusted OR (AOR) 3.91, 95\% CI 1.13 to 13.61 (listwise deletion); AOR 4.59, $95 \%$ CI 1.52 to 13.87 (imputation)) and delivery by caesarean section (AOR 2.11, 95\% CI 1.38 to 3.23 (listwise deletion); AOR 1.95, 95\% CI 1.30 to 2.92 (imputation)) showed statistically significant associations with childhood cancer in both multivariable models adjusted for maternal age, smoking and other factors simultaneously included in the models. Preterm birth (delivery before 37 completed weeks of gestation) and low birth weight, defined as a birth weight below $2500 \mathrm{~g}$, showed a significant association in the univariate analysis, but these associations were no longer significant in the multivariable model. The associations were not statistically significant on univariate or multivariable analysis between the risk of childhood cancer and hypertensive disorders,

\begin{tabular}{|c|c|c|c|}
\hline Characteristics & Cases & Controls & p Value \\
\hline Age at delivery (mean, SD) & $28.9(5.6)$ & $30.2(4.6)$ & 0.002 \\
\hline \multicolumn{4}{|l|}{ Maternal social class } \\
\hline Manual & $26(14.8 \%)$ & 79 (11.2\%) & \multirow[t]{4}{*}{0.187} \\
\hline Non-manual & $62(35.2 \%)$ & $295(41.9 \%)$ & \\
\hline Single/widowed & $87(49.4 \%)$ & $325(46.2 \%)$ & \\
\hline Missing & $1(0.6 \%)$ & $5(0.7 \%)$ & \\
\hline \multicolumn{4}{|l|}{ Paternal social class } \\
\hline Paternal manual & $71(40.3 \%)$ & $329(46.7 \%)$ & \multirow[t]{4}{*}{0.193} \\
\hline Paternal non-manual & $47(26.7 \%)$ & $183(26.0 \%)$ & \\
\hline Maternal non-manual & $57(32.4 \%)$ & $184(26.1 \%)$ & \\
\hline Missing & $1(0.6 \%)$ & $8(1.1 \%)$ & \\
\hline \multicolumn{4}{|l|}{ Marital status } \\
\hline Single/widowed/divorced/separated & $62(35.2 \%)$ & $222(31.5 \%)$ & \multirow[t]{3}{*}{0.324} \\
\hline Married & $113(64.2 \%)$ & $482(68.4 \%)$ & \\
\hline Missing & $1(0.6 \%)$ & $0(0 \%)$ & \\
\hline BMI (mean, SD; missing cases=12, missing controls $=39$ ) & $25.2(5.1)$ & $25.5(5.1)$ & 0.407 \\
\hline \multicolumn{4}{|l|}{ Smoking } \\
\hline Non-smoker & $107(60.8 \%)$ & $477(67.8 \%)$ & \multirow[t]{3}{*}{0.034} \\
\hline Smoker/ex-smoker & $68(38.6 \%)$ & $209(29.7 \%)$ & \\
\hline Missing & $1(0.6 \%)$ & $18(2.6 \%)$ & \\
\hline
\end{tabular}


Table 2 Comparison of perinatal factors between cases and controls with statistically significant ORs shown in italics

\begin{tabular}{|c|c|c|c|c|c|}
\hline Perinatal factors & $\begin{array}{l}\text { Cases } \\
\mathrm{N}=176 \\
\%\end{array}$ & $\begin{array}{l}\text { Controls } \\
\mathrm{N}=704, \%\end{array}$ & $\begin{array}{l}\text { Unadjusted OR } \\
(95 \% \mathrm{Cl})\end{array}$ & $\begin{array}{l}\text { Age and smoking } \\
\text { adjusted OR }(95 \% \mathrm{CI}) \\
\text {-listwise deletion }\end{array}$ & $\begin{array}{l}\text { Age and smoking } \\
\text { adjusted OR ( } 95 \% \mathrm{Cl}) \\
\text {-imputation of } \\
\text { missing value }\end{array}$ \\
\hline Pre-eclampsia & $11(6.3)$ & $23(3.3)$ & $1.98(0.94$ to 4.18$)$ & 1.94 (0.88 to 4.28$)$ & 1.92 (0.91 to 4.09$)$ \\
\hline $\begin{array}{l}\text { Gestational } \\
\text { hypertension }\end{array}$ & $19(10.8)$ & $71(10.1)$ & 1.09 (0.62 to 1.89$)$ & $1.21(0.67$ to 2.17$)$ & $1.13(0.64$ to 2.01$)$ \\
\hline Placenta praevia & $3(1.7)$ & $4(0.6)$ & $3.00(0.67$ to 13.40$)$ & $3.46(0.76$ to 15.65$)$ & $3.45(0.76$ to 15.62$)$ \\
\hline Abruption & $1(0.6)$ & $4(0.6)$ & $1.00(0.11$ to 8.95$)$ & $1.31(0.14$ to 12.66$)$ & $1.04(0.12$ to 9.41$)$ \\
\hline Other APH & $19(10.8)$ & 77 (10.9) & 0.99 (0.58 to 1.68$)$ & $0.98(0.56$ to 1.72$)$ & $0.96(0.56$ to 1.65$)$ \\
\hline Previous miscarriage & $18(10.2)$ & $103(14.6)$ & 0.67 (0.39 to 1.13$)$ & 0.83 (0.48 to 1.43$)$ & 0.70 (0.41 to 1.19$)$ \\
\hline Preterm birth & $24(13.6)$ & $47(6.7)$ & 2.23 (1.31 to 3.79$)$ & 2.09 (1.16 to 3.76$)$ & 2.23 (1.29 to 3.85$)$ \\
\hline Low birth weight & $17(9.7)$ & $38(5.4)$ & 1.87 (1.03 to 3.39$)$ & 1.81 (0.94 to 3.45$)$ & 1.78 (0.97 to 3.28$)$ \\
\hline Low Apgar at $1 \mathrm{~min}$ & $30(17.1)$ & 107 (15.4) & $1.14(0.73$ to 1.78$)$ & $1.14(0.71$ to 1.84$)$ & $1.15(0.73$ to 1.81$)$ \\
\hline Low Apgar at $5 \mathrm{~min}$ & $8(4.6)$ & $7(1.0)$ & $5.01(1.73$ to 14.54$)$ & 4.91 (1.46 to 16.51$)$ & $5.70(1.93$ to 16.78$)$ \\
\hline Delivery by caesarean & 55 (31.3) & $143(20.4)$ & 1.77 (1.23 to 2.56$)$ & 2.25 (1.50 to 3.36$)$ & 2.07 (1.41 to 3.05$)$ \\
\hline Instrumental delivery & $26(14.8)$ & $144(20.5)$ & $0.66(0.41$ to 1.04$)$ & $0.68(0.41$ to 1.13$)$ & $0.67(0.42$ to 1.08$)$ \\
\hline $\begin{array}{l}\text { Intrauterine growth } \\
\text { restriction }\end{array}$ & $23(13.4)$ & 71 (10.3) & 1.41 (0.85 to 2.36$)$ & 1.20 (0.68 to 2.12$)$ & 1.35 (0.80 to 2.23$)$ \\
\hline
\end{tabular}

antepartum haemorrhage, history of miscarriage or IUGR. Unlike the Apgar score at $5 \mathrm{~min}$, the score at $1 \mathrm{~min}$ did not show any association with childhood cancer.

We further investigated the types of preterm delivery (spontaneous or induced) and caesarean section (elective or emergency) as risk factors for childhood cancer and found that spontaneous and induced preterm delivery were significantly associated in the adjusted model but only delivery by emergency caesarean section remained significant on subgroup analysis (AOR 1.43, $95 \%$ CI 1.20 to 2.18 ). Furthermore, we found that the commonest indication for caesarean delivery in the infants who were subsequently diagnosed with cancer was fetal distress (data not shown).

Table 3 ORs from multivariable model

\begin{tabular}{|c|c|c|}
\hline $\begin{array}{l}\text { Perinatal } \\
\text { factors }\end{array}$ & $\begin{array}{l}\text { OR }(95 \% \mathrm{Cl}) \text { from } \\
\text { multivariable } \\
\text { model-listwise } \\
\text { deletion* }^{*}\end{array}$ & $\begin{array}{l}\text { OR }(95 \% \mathrm{Cl}) \text { from } \\
\text { multivariable } \\
\text { model- } \\
\text { imputation of } \\
\text { missing value* }\end{array}$ \\
\hline Pre-eclampsia & 1.56 (0.68 to 3.59$)$ & $1.55(0.70$ to 3.44$)$ \\
\hline $\begin{array}{l}\text { Placenta } \\
\text { praevia }\end{array}$ & $1.64(0.32$ to 8.34$)$ & 1.65 (0.32 to 8.43$)$ \\
\hline Preterm birth & 1.60 (0.76 to 3.37$)$ & 1.85 (0.92 to 3.72$)$ \\
\hline $\begin{array}{l}\text { Low birth } \\
\text { weight }\end{array}$ & $1.00(0.44$ to 2.28$)$ & $0.90(0.41$ to 1.97$)$ \\
\hline $\begin{array}{l}\text { Low Apgar at } \\
5 \mathrm{~min}\end{array}$ & 3.91 (1.13 to 13.61$)$ & 4.59 (1.52 to 13.87$)$ \\
\hline $\begin{array}{l}\text { Delivery by } \\
\text { caesarean }\end{array}$ & 2.11 (1.38 to 3.23 ) & 1.95 (1.30 to 2.92) \\
\hline
\end{tabular}

Table 4 shows the distribution of cancer sites in the 176 cases. As this table shows, the commonest sites were the brain and haemopoietic organs, especially leukaemia, but the number of cases in the subgroups was too small to allow any meaningful analysis.

\section{DISCUSSION}

We aimed to study the maternal and perinatal risk factors at the time of birth associated with the diagnosis of childhood cancer using record linkage between two-high quality registers in Scotland. We found a positive association between younger maternal age at delivery and maternal smoking with childhood cancer. In addition, preterm birth before 37 weeks of gestation, Apgar score below 7 at $5 \mathrm{~min}$ and delivery by emergency caesarean section showed statistically significant associations with childhood cancer, the last two of which remained significant in the adjusted models.

Childhood cancer is a rare condition. Case-control studies are therefore the most efficient epidemiological study design to study several risk factors at the time of birth. Cancer registries across the world have been utilised to identify cases, but finding appropriate controls remains problematic. Moreover, data collections regarding exposures by means of interviews or questionnaires are subject to recall and reporting bias. More recently, linkage of birth registers with cancer registries has been utilised to design large-scale cohort studies. However, the routine data collection is liable to lack sufficiently detailed data regarding exposure and potential confounding factors. We have tried to minimise these problems by linking two high-quality registers in Scotland. Previous validation projects have shown these databases to be $100 \%$ complete and over $97 \%$ accurate. ${ }^{15}$ Detailed 


\section{Table 4 Distribution of sites of cancer}

\begin{tabular}{|c|c|c|}
\hline Cancer site & Number & $\begin{array}{l}\text { Per } \\
\text { cent }\end{array}$ \\
\hline C22-liver and intrahepatic bile ducts & 2 & 1.14 \\
\hline C34-bronchus and lung & 2 & 1.14 \\
\hline $\begin{array}{l}\text { C41-bone and articular cartilage of } \\
\text { other and unspecified sites }\end{array}$ & 10 & 5.68 \\
\hline C49-other connective and soft tissue & 7 & 3.98 \\
\hline C52-vagina & 5 & 2.84 \\
\hline C56-ovary & 3 & 1.70 \\
\hline C62-testis & 12 & 6.82 \\
\hline C64-kidney except renal pelvis & 7 & 3.98 \\
\hline C69-eye and adnexa & 6 & 3.41 \\
\hline C71-brain & 27 & 15.34 \\
\hline $\begin{array}{l}\text { C72-spinal cord, cranial nerves, } \\
\text { other CNS }\end{array}$ & 3 & 1.70 \\
\hline C74-adrenal gland & 6 & 3.41 \\
\hline $\begin{array}{l}\text { C75-other endocrine glands and } \\
\text { related structures }\end{array}$ & 4 & 2.27 \\
\hline C76-other and ill-defined sites & 2 & 1.14 \\
\hline $\begin{array}{l}\text { C83_diffuse non-Hodgkin's } \\
\text { lymphoma }\end{array}$ & 3 & 1.70 \\
\hline $\begin{array}{l}\text { C85-other and unspecified } \\
\text { non-Hodgkin's }\end{array}$ & 2 & 1.14 \\
\hline C91-lymphoid leukaemia & 37 & 21.02 \\
\hline C92-myeloid leukaemia & 10 & 5.68 \\
\hline $\begin{array}{l}\text { C94-other leukaemias of specified } \\
\text { cell type }\end{array}$ & 2 & 1.14 \\
\hline D32-meninges & 3 & 1.70 \\
\hline $\begin{array}{l}\text { D40-Uncertain/unknown behaviour } \\
\text { male genital }\end{array}$ & 2 & 1.14 \\
\hline $\begin{array}{l}\text { D43-uncertain/unknown behaviour } \\
\text { brain and CNS }\end{array}$ & 2 & 1.14 \\
\hline $\begin{array}{l}\text { D44-uncertain/unknown behaviour } \\
\text { Endocrine }\end{array}$ & 1 & 0.57 \\
\hline $\begin{array}{l}\text { D47-uncertain/unknown behaviour of } \\
\text { lymphoid, haematopoietic and related } \\
\text { tissue }\end{array}$ & 9 & 5.11 \\
\hline $\begin{array}{l}\text { D48-uncertain/unknown behaviour } \\
\text { unknown sites }\end{array}$ & 9 & 5.11 \\
\hline
\end{tabular}

and contemporaneous recording of obstetric data in the AMND eliminated recall and reporting bias. The large number of social and demographic variables recorded in the AMND enabled incorporation of most potential covariates in the analysis. Despite these strengths to our study design, we were limited by the small number of cases and it is possible that we did not have sufficient power to detect some weak associations reported previously in the literature. Maternal and perinatal risk factors for childhood cancer appear to differ by the site of cancer in the published literature. The number of cases according to site-specific cancer diagnosis was too small in our sample to allow any subgroup analysis. Furthermore, morphology codes were not available for us to carry out more appropriate groupings of childhood cancers. This, coupled with the fact that we had to conduct our analyses on all cancers, would have made it less likely for us to find the associations that exist with site-specific cancers. This could be a major limitation of the current analysis. There was a single case of cancer that occurred within the first year of delivery. It is possible that this could be the result of the cancer being already present at birth.

The association of parental age with the diagnosis of cancer in general as well as in specific sites has been studied before. Johnson et al, ${ }^{16}$ in a pooled analysis of register linkage data from several US states, found that the risk of childhood cancer increased with increasing maternal age, while paternal age appeared to have no effect on the risk. On the other hand, several other studies, similar to the current analysis, have shown that younger maternal age was associated with an increased childhood cancer risk. ${ }^{2} 17$ There could be several explanations for the disparate findings. In a register linkage study carried out in Sweden, ${ }^{18}{ }^{19}$ researchers found that the advancing maternal age was positively associated with childhood cancer risk but only in a historical cohort. This association disappeared in a recent cohort of women although the reasons for this are unknown. Moreover, Schut ${ }^{20}$ suggests that the association of lower maternal age at the time of delivery with leukaemia in the offspring could be explained by non-response bias, although this is not applicable to the present study.

The relationship between maternal smoking and childhood cancer in the offspring is complex and controversial. While Sorahan et $a l^{1-23}$ and Edraki and Rambod $^{24}$ found an increased overall risk of childhood cancer with paternal cigarette smoking, there did not appear to be an association with maternal smoking after adjusting for birth weight. Furthermore, Pang et at did not find evidence of smoking as a risk factor for childhood cancer after adjusting for parental age. Similar associations were reported by Chang $e t a l^{25}$ with regard to ALL. The evidence appears to indicate that neonatal passive smoking plays a more important role than in utero transfer of maternal smoke-related toxins, although we cannot rule out the possibility of an association between maternal smoking and site-specific cancers. ${ }^{26}{ }^{27}$ For the current analysis, we did not have access to data on paternal smoking habits and the association seen with maternal smoking could be due to this variable acting as proxy for paternal smoking.

Other associations noted in this study have been reported before-preterm birth $^{28}$ and low Apgar score. $^{228} \mathrm{Li}$ et $a l^{29}$ found a $46 \%$ increased risk of childhood cancer in infants who had a low 5 min Apgar score. Birth weight has received a lot of attention as a risk factor for childhood cancer. While brain tumours and retinoblastoma appear to be associated with high birth weight ${ }^{30-32}$ others have found hepatoblastomas ${ }^{73}$ and gliomas ${ }^{34}$ to be associated with very low birth weight infants. Schmidt $e t a l^{28}$ observed a U-shaped relationship between birth weight and cancer risk, while Podvin et $a \hat{l}^{35}$ found birth weight adjusted for gestational age to be a better predictor than birth weight alone for the 
diagnosis of ALL, lending support to our findings. It is, however, important to note that we did not find an association with IUGR as measured by the z-score or standardised birth weight score. Dorak et $a l^{36}$ noted an association between birth weight and a diagnosis of ALL which was gender dependent, showing a non-linear association in boys.

Few studies have assessed the mode of delivery, specifically caesarean delivery, as a possible risk factor for the development of childhood cancer. Those studies have

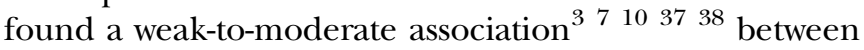
caesarean delivery and subsequent risk of developing ALL. Several hypotheses can be developed regarding the biological mechanism underpinning this association. First, caesarean delivery is likely to be a marker of adverse pregnancy and delivery events-indeed, our finding of increased emergency caesarean rates, indicated by fetal distress, seems to support this hypothesis. However, the association remained and actually became stronger, after adjusting for most other possible pregnancy complications. It was customary to use $100 \%$ oxygen to resuscitate infants born by caesarean section in the past. It is possible that this could have played a role in the subsequent development of cancer. The last explanation involves epigenetic modulations at birth. Schlinzig $e t a l^{39}$ have demonstrated altered DNA methylation in cord white blood cells after caesarean delivery and suggested that this may be the basis of increased risk of asthma, diabetes and ALL seen in infants born by caesarean section.

The association of caesarean delivery with childhood cancer seen in this analysis should be treated with caution given the small number of childhood cancer cases in the study. The recent National Institute of Health and Care Excellence (NICE) guidelines ${ }^{40}$ recommend caesarean delivery on maternal request. However, we have to remember that the majority of the caesarean deliveries seen in the cases of childhood cancer in the current analysis were emergency procedures with strong indications such as fetal distress. Our finding of the strong association of childhood cancer with caesarean delivery warrants further research using record linkage of larger cohorts or prospective follow-up of birth cohorts. From the point of view of public health interventions, the only other modifiable risk factor appears to be parental smoking. Several population-based lifestyle interventions are already under way to reduce the prevalence of smoking in pregnancy.

\section{CONCLUSION}

We found a positive association between younger maternal age at delivery and maternal smoking with childhood cancer. In addition, preterm birth, low Apgar score at $5 \mathrm{~min}$ and delivery by caesarean section showed associations with childhood cancer, which remained significant even after controlling for various covariates. These general findings should be interpreted with caution as this study did not have the power to detect any association with individual diagnostic categories of childhood cancer.

Contributors SB was responsible for designing the study, facilitating data extraction, supervising data analysis and writing of the first draft of the paper; MB analysed the data; SB, GJM and DP conceived the research idea and GJM was responsible for overall supervision. All authors contributed to the writing of the final draft of the paper. SB is the guarantor.

Funding This research was funded by the National Health Service (NHS) Grampian Endowment Fund (Project no. 10/15).

Competing interests None.

Ethics approval This research proposal was approved by the Privacy Advisory Committee of the Information and Services Division National Health Service (NHS) Scotland and the steering group of the Aberdeen Maternity and Neonatal Databank. Formal ethical approval was not considered necessary by North of Scotland Research Ethics Service as only anonymised data were analysed in this study.

Provenance and peer review Not commissioned; externally peer reviewed.

Data sharing statement No additional data are available.

Open Access This is an Open Access article distributed in accordance with the Creative Commons Attribution Non Commercial (CC BY-NC 3.0) license, which permits others to distribute, remix, adapt, build upon this work noncommercially, and license their derivative works on different terms, provided the original work is properly cited and the use is non-commercial. See: http:// creativecommons.org/licenses/by-nc/3.0/

\section{REFERENCES}

1. Information and Services Division, NHS Scotland. Cancer incidence and mortality statistics. http://www.isdscotland.org/Health-Topics/ Cancer/Publications (accessed 28 Jan 2013).

2. Johnson KJ, Puumala SE, Soler JT, et al. Perinatal characteristics and the risk of neuroblastoma. Int J Cancer 2008;123:1166-72.

3. Bluhm E, McNeil DE, Cnattingius S, et al. Prenatal and perinatal risk factors for neuroblastoma. Int J Cancer 2008;123:2885-90.

4. Roman E, Simpson J, Ansell P, et al. Perinatal and reproductive factors: a report on haematological malignancies from the UKCCS. Eur J Cancer 2005;41:749-59.

5. Cantwell MM, Forman MR, Middleton RJ, et al. Association of early life factors and brain tumour risk in a cohort study. $\mathrm{Br} \mathrm{J}$ Cancer 2008;99:796-9.

6. Mallol-Mesnard N, Menegaux F, Lacour B, et al. Birth characteristics and childhood malignant central nervous system tumours: the ESCALE study (French Society for Childhood Cancer). Cancer Detect Prev 2008;32:79-86.

7. McLaughlin CC, Baptiste MS, Schymura MJ, et al. Birth weight, maternal weight and childhood leukaemia. Br J Cancer 2006;94:1738-44.

8. MacArthur AC, McBride ML, Spinelli JJ, et al. Risk of childhood leukaemia associated with parental smoking and alcohol consumption prior to conception and during pregnancy: the cross-Canada childhood leukaemia study. Cancer Causes Control 2008;19:283-95.

9. Pang D, McNally R, Birch JM. Parental smoking and childhood cancer: results from the United Kingdom Childhood Cancer Study. Br J Cancer 2003;88:373-81.

10. Adami J, Glimelius B, Cnattingius S, et al. Maternal and perinatal factors associated with Non-Hodgkin's lymphoma among children. Int J Cancer 1996;65:774-7.

11. Gold EB, Leviton A, Lopez R, et al. Parental smoking and risk of childhood brain tumors. Am J Epidemiol 1993;137:620-8.

12. Milne $\mathrm{E}$, Laurvick $\mathrm{CL}$, Blair $\mathrm{E}$, et al. Fetal growth and the risk of childhood CNS tumours and lymphomas in Western Australia. Int $J$ Cancer 2008;123:436-43.

13. Paltiel O, Harlap S, Deutsch L, et al. Birth weight and other risk factors for acute leukaemia in the Jerusalem Perinatal Study cohort. Cancer Epidemiol Biomarkers Prev 2004;13:1057-64.

14. Campbell D, Hall M, Lemon J, et al. Clinical birthweight standards for a total population in the 1980s. BJOG 1993;100:436-45.

15. Cole S. Scottish maternity and neonatal records. 8th Study Group of the Royal College of Obstetricians and Gynaecologists, 1980:39-52. 
16. Johnson KJ, Carozza SE, Chow EJ, et al. Parental age and risk of childhood cancer: a pooled analysis. Epidemiology 2009;20:475-83.

17. Schüz J, Kaatsch $\mathrm{P}$, Kaletsch U, et al. Association of childhood cancer with factors related to pregnancy and birth. Int $J$ Epidemiol 1999;28:631-9.

18. Maule MM, Merletti F, Pastore G, et al. Effects of maternal age and cohort of birth on incidence time trends of childhood acute lymphoblastic leukemia. Cancer Epidemiol Biomarkers Prev 2007;16:347-51.

19. Maule MM, Vizzini L, Czene K, et al. How the effect of maternal age on the risk of childhood leukemia changed over time in Sweden, 1960-2004. Environ Health Perspect 2009;117:299-302.

20. Schüz J. Non-response bias as a likely cause of the association between young maternal age at the time of delivery and the risk of cancer in the offspring. Paediatr Perinat Epidemiol 2003;17:106-12.

21. Sorahan T, Lancashire RJ, Hultén MA, et al. Childhood cancer and parental use of tobacco: deaths from 1953 to 1955. Br J Cancer 1997;75:134-8.

22. Sorahan T, McKinney PA, Mann JR, et al. Childhood cancer and parental use of tobacco: findings from the inter-regional epidemiological study of childhood cancer (IRESCC). Br J Cancer 2001;84:141-6.

23. Sorahan T, Prior P, Lancashire RJ, et al. Childhood cancer and parental use of tobacco: deaths from 1971 to 1976 . Br J Cancer 1997;76:1525-31.

24. Edraki M, Rambod M. Parental smoking and risk of childhood cancer: hospital-based case-control study in Shiraz. East Mediterr Health J 2011:17:303-8.

25. Chang JS, Selvin S, Metayer C, et al. Parental smoking and the risk of childhood leukemia. Am J Epidemiol 2006;163:1091-100.

26. Mucci LA, Granath F, Cnattingius S. Maternal smoking and childhood leukemia and lymphoma risk among 1,440,542 Swedish children. Cancer Epidemiol Biomarkers Prev 2004;13:1528-33.

27. Stavrou EP, Baker DF, Bishop JF. Maternal smoking during pregnancy and childhood cancer in New South Wales: a record linkage investigation. Cancer Causes Control 2009;20:1551-8.
28. Schmidt LS, Schüz J, Lähteenmäki $P$, et al. Fetal growth, preterm birth, neonatal stress and risk for CNS tumors in children: a Nordic population- and register-based case-control study. Cancer Epidemiol Biomarkers Prev 2010;19:1042-52.

29. Li J, Cnattingius S, Gissler M, et al. The 5-minute Apgar score as a predictor of childhood cancer: a population-based cohort study in five million children. BMJ Open 2012;2:e001095.

30. Harder T, Plagemann A, Harder A. Birth weight and risk of neuroblastoma: a meta-analysis. Int J Epidemiol 2010;39:746-56.

31. Daling JR, Starzyk P, Olshan AF, et al. Birth weight and the incidence of childhood cancer. J Natl Cancer Inst 1984;72:1039-41.

32. MacLean J, Partap S, Reynolds P, et al. Birth weight and order as risk factors for childhood central nervous system tumors. J Pediatr 2010;157:450-5.

33. Spector LG, Johnson KJ, Soler JT, et al. Perinatal risk factors for hepatoblastoma. Br J Cancer 2008;98:1570-3.

34. Spector LG, Puumala SE Carozza SE et al Cancer risk among children with very low birth weights. Pediatrics 2009;124:96-104.

35. Podvin D, Kuehn CM, Mueller BA, et al. Maternal and birth characteristics in relation to childhood leukaemia. Paediatr Perinat Epidemiol 2006;20:312-22.

36. Dorak MT, Pearce MS, Hammal DM, et al. Examination of gender effect in birthweight and miscarriage associations with childhood cancer (United Kingdom). Cancer Causes Control 2007;18:219-28.

37. Cnattingius S, Zack M, Ekbom A, et al. Prenatal and neonatal risk factors for childhood myeloid leukaemia. Cancer Epidemiol Biomarkers Prev 1995;4:441-5.

38. Kaye SA, Robinson LL, Anthony Smithson W, et al. Maternal reproductive history and birth characteristics in childhood acute lymphoblastic leukaemia. Cancer 1991;68:1351-5.

39. Schlinzig T, Johansson S, Gunnar A, et al. Epigenetic modulation at birth-altered DNA methylation in white blood cells after caesarean section. Acta Paediatr 2009;98:1096-9.

40. National Institute of Health and Care Excellence. CG132 caesarean section. http://guidance.nice.org.uk/CG132 (accessed Mar 2012). 